\title{
Claudio Lagomarsini, Il 'Roman de Cardenois' e la tradizione manoscritta di Guillaume de Machaut
}

\section{Maria Colombo Timelli}

\section{(2) OpenEdition}

1 Journals

\section{Édition électronique}

URL : https://journals.openedition.org/studifrancesi/2986

DOI : $10.4000 /$ studifrancesi.2986

ISSN : 2421-5856

Éditeur

Rosenberg \& Sellier

\section{Édition imprimée}

Date de publication : 1 juillet 2013

Pagination : 428-429

ISSN : 0039-2944

\section{Référence électronique}

Maria Colombo Timelli, « Claudio Lagomarsini, I/ 'Roman de Cardenois' e la tradizione manoscritta di Guillaume de Machaut », Studi Francesi [En ligne], 170 (LVII | II) | 2013, mis en ligne le 30 novembre 2015, consulté le 02 février 2023. URL : http://journals.openedition.org/studifrancesi/2986 ; DOI : https://doi.org/10.4000/studifrancesi.2986

Ce document a été généré automatiquement le 2 février 2023.

\section{(c) $($ ) $\odot$ (8Y NO ND}

Creative Commons - Attribution - Pas d'Utilisation Commerciale - Pas de Modification 4.0 International - CC BY-NC-ND 4.0

https://creativecommons.org/licenses/by-nc-nd/4.0/ 
Claudio Lagomarsini, Il 'Roman de Cardenois' e la tradizione manoscritta di Guillaume de Machaut

Maria Colombo Timelli 


\section{RÉFÉRENCE}

ClAUdio lagomarsini, Il 'Roman de Cardenois' e la tradizione manoscritta di Guillaume de Machaut, in «Romania», 130, 2012, pp. 109-133.

Le Roman de Cardenois, roman anonyme en prose très peu connu, a été composé en milieu aragonais vers la fin du XIV siècle (ignoré par le Dictionnaire des Lettres Françaises, il l'est également dans Arlima): son intérêt réside, plutôt que dans ses mérites littéraires, franchement modestes, dans la place qu'il fait à une dizaine d'insertions lyriques de Guillaume de Machaut, ainsi que dans la réécriture en prose du portrait de dame Passebeauté, tiré du Jugement du roi de Behaigne. C.L. se pose ici la question du rapport entre les pièces lyriques enchâssées dans Cardenois et la tradition textuelle, particulièrement complexe comme on le sait, du corpus machautien, dans le but de repérer, si possible, le manuscrit (ou la famille de manuscrits) que le prosateur pourrait avoir eu sous les yeux. L'analyse suit trois étapes: après une liste des insertions lyriques dans le roman, rappel de la tradition manuscrite de Machaut et des différents stemmas proposés à partir de l'édition Hoepffner (1908-1921), discussion des loci critici susceptibles d'indiquer quelque rapport entre les pièces insérées dans Cardenois et les manuscrits des poèmes. Les conclusions, présentées avec la prudence qu'impose ce type d'enquête, semblent indiquer un rapport privilégié avec la «constellation Vg»: puisque le chansonnier Vega-Aguiló est le seul témoin conservé de Machaut rattaché à la cour aragonaise de Violant de Bar, le Roman de Cardenois s'avère un témoignage des plus intéressants de la composition, copie et circulation de textes français vers la fin du Moyen Âge. 